\title{
A Generalized Model for Predicting Yarn Global Quality Index
}

\author{
H. Souid*, M. Sahnoun, A. Babay and M. Cheikrouhou
}

Textile Research Unit of ISET of Ksar-Hellal, B.P 68, Avenue Hadj Ali SOUA, 5070 Ksar Hellal, Tunisia

\begin{abstract}
In this work we tried to predict Ring spun yarn quality from fiber properties, yarn count and twist by using a back-propagation network. First, we have proceeded with principal component and path analyses to extract and to visualize the main characteristics of the data set. Then, a model was constructed using neural network to optimize final yarn quality. The study of yarn quality was based on the desirability approach. The present method allowed us to quantify yarn quality by an index belonging to the interval $[0,1]$ which includes major physical properties of cotton Ring spun yarn. It can be optimized by using an algorithm, which is modified when criteria requirements of yarn quality are changed. All these methods have contributed to establish a convenient model that could predict global yarn quality.
\end{abstract}

Keywords: Desirability, neural network, optimization, quality, ring spun yarn.

\section{INTRODUCTION}

Yarn quality is generally qualified through one parameter which is namely its strength [1-10]. Yunus and Rhman [11] have established a yarn quality index including three parameters which are strength, elongation and uniformity (Eq. 1).

Yarn Quality Index $=\frac{\text { Elongation } \times \text { Strength }}{\text { Uniformity }}$

Hence, it is now an accepted principle that 'satisfying the customer' in all respects is in practice what we mean by quality [12]. Although the quality of any product instead yarn is a multi-criteria phenomena that requires simultaneous satisfaction of its properties [13]. Until recently, in spinning domain, defining a global yarn quality index that encloses major physical properties still remains unstudied. In this paper, we tried to develop a model for predicting an overall quality of ring spun cotton yarns combining simultaneously major yarn parameters by using artificial neural networks. This method is one of the so-called soft computing techniques. It is based on learning systems for modeling and optimization that have been increasingly applied to textile problems during the last 30 years [14]. For this goal, an algorithm of cotton fiber selection has been developed.

\section{MATERIALS AND METHODS}

Yarn quality encloses its different properties in the same time. In order to better express yarn quality, we have tried in this survey to consider major known yarn properties. Thus, we have studied the following yarn aspects (Table 1).

We have made the database based on the major cotton fiber characteristics which is composed of twelve

*Address correspondence to this author at the Textile Research Unit of ISET of Ksar-Hellal, B.P 68, Avenue Hadj Ali SOUA, 5070 Ksar Hellal, Tunisia; Tel: 00216 97086208; Fax (+216) 73475 163;

E-mail: ajirsou2000@voila.fr characteristics. The summary of statistics of fiber parameters is shown in Table 2.

\section{PRINCIPAL COMPONENT AND PATH ANALYSES APPLICATION}

In the first part of this work, we have applied principal components methodology PCA on fiber distribution using NemrodW software. This study was achieved for two aims:

- First, to search the main fiber characteristics those mostly contribute to yarn quality.

- Secondly, to reduce the number of fiber variables considered as inputs in order to compute better performance of the network model.

To reduce the dimension of fiber data composed of 12 characteristics with PCA method, we tried to determine the "best" eigenvectors of the covariance matrix. The eigenvectors corresponding to the largest eigenvalues are also called "principal components".

Several groups were identified on the basis of principal component analysis (Fig. 1). The unit circle showing the correlation of fiber properties with the first two principal axes illustrated in Fig. (1) presents three groupings well delineated. We can account these groupings as mentioned in Table 3.

Principal component analysis (PCA) offers a simple and useful mode of data graphical-reduction [15], but it doesn't locate the most significant fiber characteristic of the group in yarn quality. In order to find which is the convenient fiber parameter to choose from each group, data were then analyzed by multiple regression techniques and path model analysis. Hence, we have defined a percent relative contribution for each fiber property $\left(C_{i}(\%)\right)$ as follow:

$$
C_{i}(\%)=100 \times R^{2} \times \frac{\beta_{i}}{\sum_{1}^{k} \beta_{i}}
$$


Table 1. Summary Statistics for Ring Spun Yarn Properties

\begin{tabular}{|c|c|c|c|c|c|}
\hline Yarn Property & Symbol & Mean & Standard Deviation & Minimum Value & Maximum Value \\
\hline Tenacity (cN.Tex-1) & RKM & 17,32 & 1,23 & 14,64 & 22,12 \\
\hline Tenacity evenness (\%) & CVRKM & 6,85 & 3,17 & 4,54 & 7,96 \\
\hline Breaking elongation (\%) & $\mathrm{E} \%$ & 7,87 & 0,77 & 6,27 & 9,72 \\
\hline Breaking work (Joule) & TR & 2,83 & 0,85 & 1,27 & 6,58 \\
\hline Unevenness yarn (\%) & $\mathrm{U} \%$ & 9,92 & 0,96 & 7,37 & 12,32 \\
\hline Number of thick points & THIK & 54,29 & 18,59 & 2,75 & 179,50 \\
\hline Number of thin points & THIN & 1,46 & 3,76 & 2,00 & 19,43 \\
\hline Number of neps & BOUT & 64,09 & 17,37 & 0,45 & 220,20 \\
\hline Hairiness & PILO & 9,74 & 6,11 & 6,62 & 11,84 \\
\hline Twist value (turn.m-1) & Twist & 463 & 66,65 & 364 & 629 \\
\hline Yarn count $\left(\mathrm{m} .10^{3} \mathrm{~kg}\right)$ & $\mathrm{Nm}$ & 13,07 & 3,46 & 10,10 & 21,12 \\
\hline
\end{tabular}

Table 2. Summary Statistics for Fiber Parameters

\begin{tabular}{|c|c|c|c|c|c|c|}
\hline Fiber Property & Symbol & Instrument & $\begin{array}{l}\text { Mean } \\
\text { Value }\end{array}$ & $\begin{array}{l}\text { Standard } \\
\text { Deviation }\end{array}$ & $\underset{\text { Value }}{\text { Minimum }}$ & $\underset{\text { Value }}{\text { Maximum }}$ \\
\hline Micronaire index $(\mu \mathrm{g} / \mathrm{inch})$ & Mic & HVI & 4,30 & 0,18 & 4,00 & 4,70 \\
\hline $\begin{array}{l}\text { Upper Half Mean Length (UHML) } \\
\qquad\left(10^{-3} \mathrm{~m}\right)\end{array}$ & Len & HVI & 28,44 & 0,68 & 27,40 & 30,60 \\
\hline Strength $\left(\mathrm{cN} \cdot\right.$ tex $\left.^{-1}\right)$ & Str & HVI & 29,32 & 1,56 & 26,00 & 34,90 \\
\hline Elongation (\%) & Elg & HVI & 6,53 & 0,80 & 4,90 & 8,20 \\
\hline Trash count & $\operatorname{Tr} \mathrm{cnt}$ & HVI & 11,52 & 4,47 & 2,00 & 24,00 \\
\hline Trash area & $\operatorname{Tr}$ area & HVI & 0,14 & 0,03 & 0,07 & 0,24 \\
\hline Yellowness & $+b$ & HVI & 10,08 & 0,88 & 9,20 & 14,30 \\
\hline
\end{tabular}

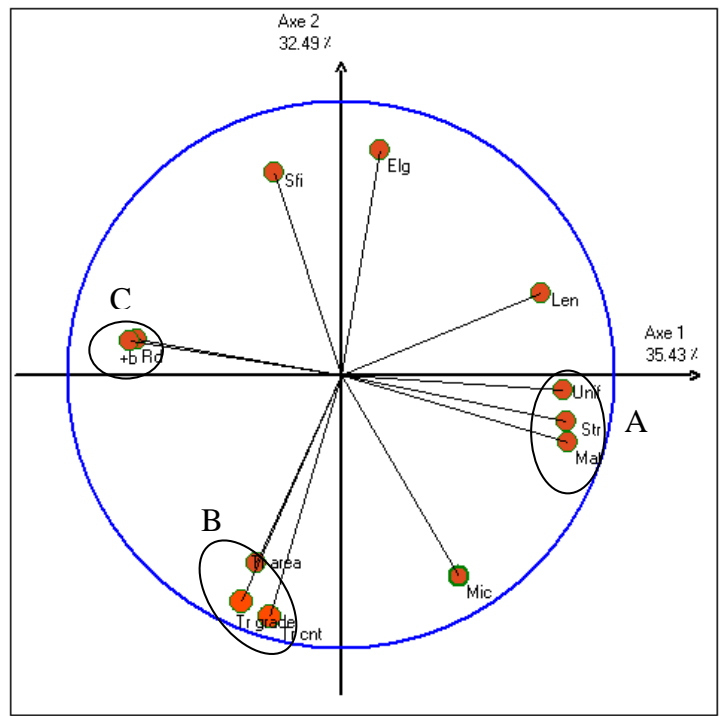

Fig. (1). Unit circle showing the correlation of fibber properties with the first two principal axes. 
Table 3. PCA Fiber Properties Classification

\begin{tabular}{|c|c|}
\hline Grouping & Fiber Property \\
\hline \hline \multirow{3}{*}{ Group A } & Str \\
\cline { 2 - 2 } & Unif \\
\cline { 2 - 2 } & Mat \\
\hline \multirow{2}{*}{ Group B } & Tr grade \\
\cline { 2 - 2 } & Tr area \\
\cline { 2 - 2 } & Tr cnt \\
\hline \multirow{2}{*}{ Group C } & Rd \\
\cline { 2 - 2 } & $+\mathrm{b}$ \\
\hline
\end{tabular}

$\mathrm{R}$ is the coefficient of determination

$\beta_{i}$ is the standardized coefficient of the $\mathrm{i}^{\text {th }}$ fiber property

We determined the percent relative contributions of fiber properties from the values of the standardized multiple regression coefficients [5]. These constants represent the path coefficients.

As the quality of a yarn is simultaneously attributed to different characteristics, we have calculated the mean contribution of each fiber property factor on the different yarn properties. The path analysis indicates that in ring spun spinning, strength, trash count and reflectance have the major contribution on their corresponding groups.

We will consider only the fiber parameters which have the highest contribution $C_{i}(\%)$ of each group as mentioned in Table 4. Hence, from twelve fiber characteristics, seven will be considered for studying yarn quality, which are Strength (str), Trash count (tr cnt), Greyness (Rd), Short Fiber index (Sfi), Elongation (Elg), Upper Half Mean Length (Len) and micronaire (Mic).

\section{DETERMINATION OF AN OVERALL YARN QUALITY INDEX}

The overall quality index of the yarn $(D)$ is defined by using the Derringer and Suich [16] composite desirability function as follow:

$$
D=\sqrt[s]{d_{1}^{s_{1}} \times d_{2}^{s_{2}} \times \ldots \times d_{n}^{s_{n}}}
$$

$s=\sum s i ; s_{i}$ is the weight of $\mathrm{i}^{\text {th }}$ response

$d_{i}$ is the individual desirability of each response. Individual desirability is a function of the objective of the response. It can be maximized, minimized or targeted.

Yarn responses to be maximized are tenacity (RKM), breaking work energy (TR) and elongation (E \%). The corresponding desirability function used for this case is as follow:

$$
d_{i}=\left\{\begin{array}{ccc}
0 & \text { if } & Y_{i} \leq L_{i} \\
{\left[\frac{Y_{i}-L_{i}}{T_{i}-L_{i}}\right]^{p}} & \text { if } & L_{i} \leq Y_{i} \leq T_{i} \\
1 & \text { if } & Y_{i} \geq T_{i}
\end{array}\right.
$$

$L_{i}, U_{i}$ and $T_{i}$ are respectively the lower, upper, and target values, that are desired for response $Y_{i}$, with $L_{i} Y_{i} U_{i}$.

$P$ is the weight of desirability function of $i^{\text {th }}$ response. It depends on the customer exigency. The weight defines the shape of the desirability function for each response. For each response, you can select a weight (from 0.1 to 10) to emphasize or de-emphasize the target. A weight

Less than one (minimum is 0.1) places less emphasis on the target

Equal to one places equal importance on the target and the bounds

Greater than one (maximum is 10) places more emphasis on the target

If a response is to be minimized instead such as CVRKM, regularity (U \%), Hairiness (PILO), number of thick points THICK, number of thin points THIN or number of neps BOUT, the individual desirability is defined as:

$$
d_{i}=\left\{\begin{array}{ccc}
1 & \text { if } & Y_{i} \leq T_{i} \\
{\left[\frac{Y_{t}-U_{t}}{T_{i}-U_{t}}\right]^{q}} & \text { if } & T_{i} \leq Y_{i} \leq U_{t} \\
0 & \text { if } & Y_{i} \geq U_{i}
\end{array}\right.
$$

\begin{tabular}{|c|c|c|c|c|c|c|c|c|c|c|c|}
\hline & & RKM & CV RKM & E\% & TR & U\% & PILO & THIK & THIN & BOUT & AVERAGE \\
\hline \multirow{3}{*}{ GROUP A } & Str & 3.37 & 22.26 & 0.12 & 2.34 & 3.14 & 16.12 & 9.34 & 8.82 & 8.13 & 8.18 \\
\hline & Unif & 16.94 & 0.08 & 3.80 & 4.43 & 8.28 & 2.24 & 6.84 & 4.30 & 0.00 & 5.21 \\
\hline & Mat & 4.75 & 7.85 & 2.59 & 1.12 & 6.69 & 10.19 & 9.34 & 10.62 & 8.94 & 6.90 \\
\hline \multirow{3}{*}{ GROUP B } & Tr cnt & 2.10 & 5.66 & 12.82 & 20.35 & 12.25 & 6.42 & 11.61 & 9.94 & 7.28 & 9.82 \\
\hline & Tr area & 2.06 & 4.06 & 1.79 & 10.46 & 10.22 & 12.97 & 5.82 & 8.13 & 13.48 & 7.67 \\
\hline & Tr grade & 2.24 & 4.05 & 11.15 & 2.53 & 4.19 & 2.46 & 8.26 & 0.72 & 0.97 & 4.06 \\
\hline \multirow{6}{*}{ GROUP C } & Rd & 9.52 & 7.00 & 2.13 & 5.60 & 4.85 & 4.65 & 1.66 & 3.14 & 3.73 & 4.70 \\
\hline & $+\mathbf{b}$ & 3.81 & 5.09 & 7.17 & 4.53 & 1.77 & 6.90 & 2.27 & 3.36 & 3.36 & 4.25 \\
\hline & Sfi & 2.61 & 8.21 & 3.14 & 6.23 & 12.67 & 7.03 & 14.86 & 8.56 & 6.78 & 7.79 \\
\hline & Elg & 3.41 & 9.37 & 9.10 & 2.82 & 0.92 & 0.82 & 1.62 & 5.72 & 2.43 & 4.02 \\
\hline & Len & 18.36 & 1.22 & 3.69 & 8.03 & 10.07 & 0.59 & 5.11 & 8.30 & 2.88 & 6.47 \\
\hline & Mic & 3.03 & 10.45 & 12.21 & 12.27 & 4.85 & 8.10 & 2.67 & 5.59 & 4.27 & 7.05 \\
\hline
\end{tabular}

Table 4. Relative Contribution of Fiber Properties to Yarn Properties $C_{i}(\%)$ 
Table 5. Input and Output Parameters of the Neural Network Model

\begin{tabular}{|c|c|c|c|}
\hline \multirow{4}{*}{ Fiber Properties } & Strength & Str \\
\cline { 3 - 4 } & & Trash count & $\begin{array}{c}\mathrm{Tr} \\
\mathrm{cnt}\end{array}$ \\
\cline { 3 - 4 } & \multirow{4}{*}{ Inputs } & $\begin{array}{c}\text { Greyness (colour } \\
\text { reflectance) }\end{array}$ & $\mathrm{Rd}$ \\
\cline { 3 - 4 } & & Short Fiber index & SFI \\
\cline { 3 - 4 } & & Elongation & Elg \\
\cline { 3 - 4 } & & $\begin{array}{c}\text { Upper Half Mean } \\
\text { Length (UHML) }\end{array}$ & Len \\
\cline { 3 - 4 } & \multirow{3}{*}{ Construction parameter } & Micronaire index & Mic \\
\cline { 3 - 4 } & & Yarn count & Nm \\
\hline Output & Ring Spun yarn global quality & \multicolumn{2}{|c|}{$D$} \\
\hline
\end{tabular}

Where $q$ is the weight of desirability function of the $i^{\text {th }}$ response.

Hence, for each yarn response, an individual desirability value is calculated. Then, yarn quality index is determined by geometric mean of these individual desirabilities as mentioned in equation 3. The objectives of maximizing, minimizing or targeting a response depends on customer quality requirements.

\section{NEURAL NETWORK MODELING: MODEL PARA-METERS}

In the experiment, we have tried a back-propagation neural net consisting of adjusting the weights until reaching a minimum error value between the actual and predicted quality index.

The fiber parameters generated from principal component and path studies constitutes the network inputs. Seven inputs were then considered instead of twelve in the training database as shown in Table $\mathbf{5}$.

The network should have one output neuron since there is one target which is the yarn quality index defined by composite desirability. The output parameter corresponds to yarn quality index $D$ which includes the physical parameters described in Table $\mathbf{1}$.

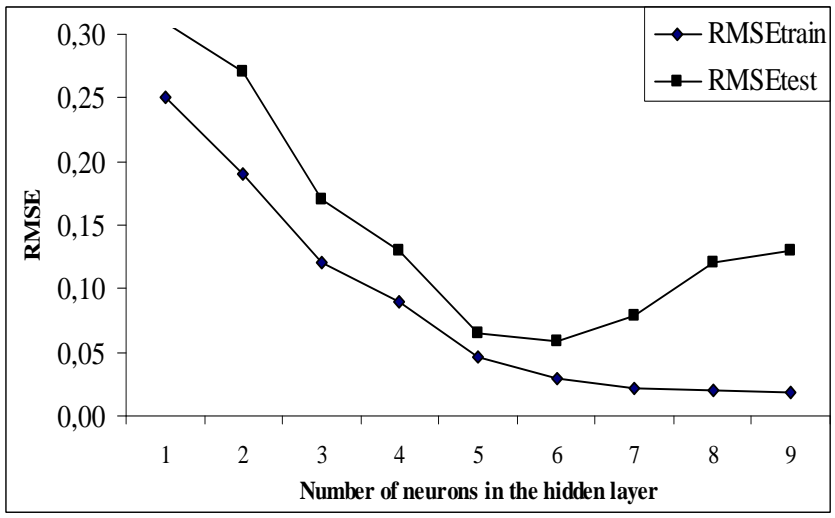

(a)
As the outputs were scaled between zero and 1, the convenient transfer function used in the hidden layer that squash the values between 0 and 1 corresponds to the log sigmoid activation function (Eq. 6) [17].

$F(x)=1 /(1+\exp (-x))$

The activation function of the output layer that has improved the best forecasting of the model is the linear activation function. Output is calculated according to the following equation:

$G(x)=x$

The choice of the number of hidden neurons is adjusted by trial until having the lowest error [17].

\section{TRAINING WITH ARTIFICIAL NEURAL NET-WORKS}

We train the network on the database composed of 175 samples. Programming the network architecture, training and testing were performed by using MATLAB software. In order to determine calculations performances during iterative training and execution, we calculated the sum of the squared differences between the target and actual output values on the output global desirability which constitutes error. Two error values were considered to evaluate the model performance:

- The root mean square error generated by the training data (Eq. 8)

$$
R M S E_{\text {train }}=\left[\frac{\sum_{1}^{N} \mid\left(y_{i}-\left.g\left(x_{i}, w\right)\right|^{2}\right.}{N}\right]^{\frac{1}{2}}
$$

$N$ : Number of training data points $=80 \%$ of database

$y_{i}$ : Yarn quality index measured in the training database corresponding to the input $x_{i}$

$g\left(x_{i}, w\right)$ : Yarn quality index calculated by the neural network corresponding to the input $x_{i}$ for a weight value $w$

$y_{i}-g\left(x_{i}, w\right)$ : The individual error

- The mean square root error generated by the test data (Eq. 9)

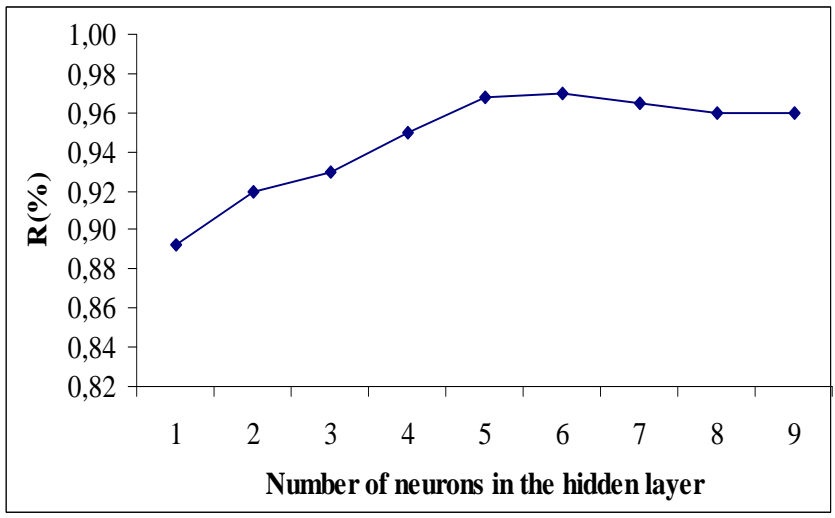

(b)

Fig. (2). Time series plot of $R M S E_{\text {train }}, R M S E_{\text {test, }}$ (a) and correlation coefficient $R$ (b) against the number of hidden nodes. 


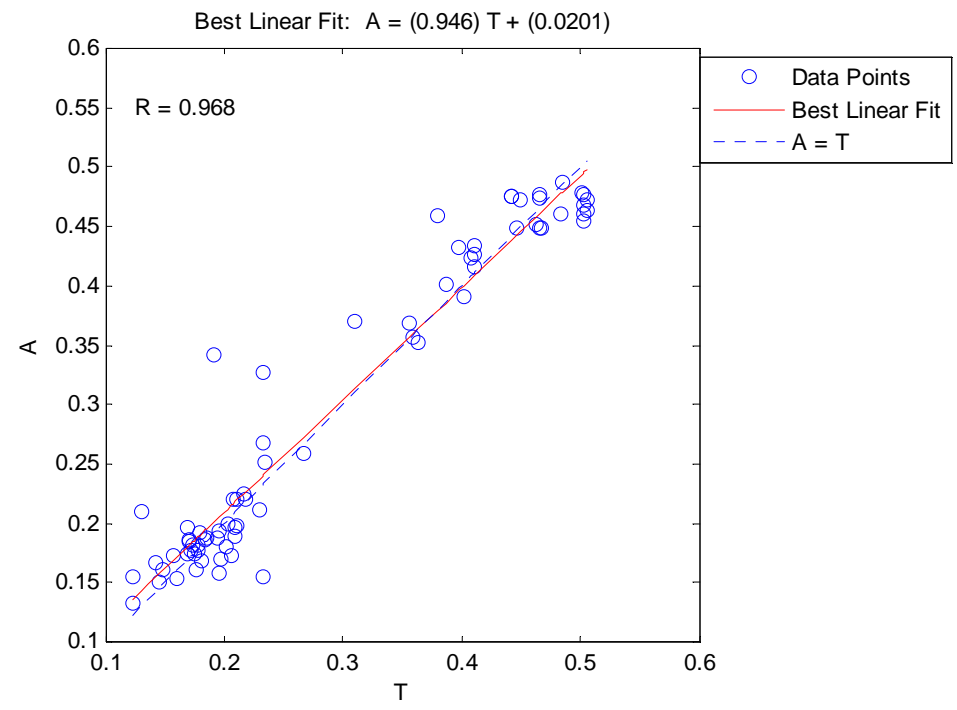

Fig. (3). Relationship between actual and predicted values of the global yarn quality index.

$R M S E_{\text {test }}=\left[\frac{\sum_{1}^{P} \mid\left(y_{i}-\left.g\left(x_{i}, w\right)\right|^{2}\right.}{P}\right]^{\frac{1}{2}}$

$P$ : Number of test data points $=20 \%$ of input-output data pairs were used as the test set.

For each learned data pair, a forward pass and backwards pass is performed. This is repeated over and over again until the error is at a low enough level (Fig. 2a). The network training ends when the mean squared errors have reached the minimum. We have applied 200 iterations.

After some trails with 1 to 4 hidden nodes, the memorization of the network is decreased. In the other side, increasing the number of hidden nodes higher than 5 involved higher difference between the actual and predicted yarn quality value (Fig. 2a). The right number of nodes set reproducing comparable errors (Fig. 2a) corresponds to five hidden nodes.

With five nodes in the hidden layer, the lowest mean square root errors generated by the training and test data are respectively equal to 0,047 and 0,073. The training set error $R M S E_{\text {train }}$ and the test set error $R M S E_{\text {test }}$ are subsequently small and show similar characteristics.

The third variable emphasizing the good performance of the modeling is the correlation coefficient ( $R$-value) between the outputs and targets in the test data (Fig. 2b). It is a measure of how well the variation in the output is explained by the targets. If this number is equal to 1 , then there is perfect correlation between targets and outputs. With five nodes in the hidden layer, the correlation coefficient between the computed outputs and the desired targets is highest (Fig. 2b) and equals to 0,968 , which is very close to 1 . The network found has consequently a good performance.

The following Fig. (3) illustrates the network outputs (A) plotted versus the targets (T) as open circles. The best linear fit is indicated by a dashed line. The perfect fit (output equal to targets) is indicated by the solid line. Here, the fit is good as the best fit line is very close to the perfect fit line.

\section{CONCLUSION}

In our study, quality was evaluated with an index that can be situated between zero and one. The developed method does not consider single properties separately but combine several yarn properties simultaneously through desirability approach. Fibers characteristics, treated as inputs, are firstly reduced using PCA and contribution percentage in order to find the best set to characterize the overall yarn quality in order to facilitate modeling. Then, we have modelled yarn quality index in order to foresee it starting from main fiber properties. This inspection was attained by using neural networks tools. The present approach has given an objective evaluation of composite quality by a multi-criteria optimization. The model performance was high as shown by errors and correlation values. Accordingly, the use of desirability approach with combination of neural network could be a good application for assessing yarn quality optimization.

\section{CONFLICT OF INTEREST}

None declared.

\section{ACKNOWLEDGEMENT}

None declared.

\section{REFERENCES}

[1] L. Cheng, and D.L. Adams, "Yarn strength prediction using neural networks. Part1: Fiber properties and yarn strength relationship", Text. Res. J., vol. 65 (9), pp. 495-500, 1995.

[2] Mc. Ramesh, R. Rajamaniachan and S. Jayaraman, "The prediction of yarn tensile properties by using artificial neural networks", Text. Res. J., vol. 86, pp. 459-468, 1995.

[3] S. Sette, L. Boullart, L. Vangenhove and P. Kiekens, "Optimizing the fiber-to-yarn production process with a combined neural network / Genetic Algorithm Approach", Text. Res, J., vol 67, part (2), pp. 84-92, 1997.

[4] R. Rangaswamy, M. S. Hassen, and S. Jayaraman, "Analysis of the modeling methodologies for predicting the strength of Air-Jet spun yarns", Text. Res. J., vol 67, pp. 39-44, 1997. 
[5] Y. El Mogahzy, Jr. R. Broughton and W.K. Lynch, "A statistical approach for determining the technological value of cotton using HVI fiber properties", Text. Res. J., vol. 59, pp. 495-500, 1990.

[6] N. Pan, T. Hua and Y. Qiu, "Relationship between fiber and yarn strength", Text. Res. J., vol. 71, pp. 960-964, 2001.

[7] S. Maatoug, N. Ladhari and F. Sakli, "Viscoelastic behaviour of starch sized warps", J. Appl. Sci., vol. 7, no. 16, pp. 2376-2379, 2007.

[8] B.R. Das, S.M. Ishtiaque and R. S. Rengasamy, "Static failure mechanism of staple yarns: A critical review", Asian. J. Text., vol. 1, no. 1, pp. 50-58, 2011.

[9] B.A. Sami and H. Naima, "Prediction of the mechanical behaviour of open end and ring spun yarns", J. Appl. Sci., vol. 9, no. 5, pp.1466-1473, 2009.

[11] M. Yunus and F. Rhman, "Micronaire Effects", Text. Asia., vol. 13, pp. 58-61, 1990
[12] A.R. Roach, "Meeting customer needs for textiles and clothing", $J$ Text. Inst., vol. 85, no. 4, pp. 484-495, 1994.

[13] S.C. Winchester, "Total management in textiles", J. Text. Inst., vol. 85, no. 4, pp. 445-459, 1994.

[14] S. Sette and L. V. Langenhove, "An overview of soft computing in textiles", J. Text. Inst., vol 94, pp.103-109, 2003.

[15] F. Caillez and J-P. Pages "Introduction à l'analyse des données", 1976

[16] G.C. Derringer and R. Suich, "Simultaneous optimization of several response variables", J. Quality Technol., vol. 12, part(4), pp. 214-219, 1980.

[17] G. Dreyfus, M. Martinez, M. Samuelides, M.B. Gordan, F. Badran, S. Thiria and L. Hérault, "Réseaux de Neurones: Méthodologie et Application", Editions Eyrolles, Paris, vol. 1, pp. 4-52, 2002.

(C) Souid et al.; Licensee Bentham Open.

This is an open access article licensed under the terms of the Creative Commons Attribution Non-Commercial License (http: //creativecommons.org/licenses/by$\mathrm{nc} / 3.0 /$ ), which permits unrestricted, non-commercial use, distribution and reproduction in any medium, provided the work is properly cited. 